\title{
Entropy Evaluation of Industrial Upgrading of Mining Area
}

\author{
Shuailing Ji, Rui Zhang \\ School of Management, China University of Mining and Technology, Beijing, 100083, China
}

\begin{abstract}
In order to solve the problem that the economic growth and the development of enterprises constrained by the industrial development of mining area, the paper establishes model of entropy evaluation of industrial upgrading of mining area. Firstly, the evaluation index system is given by analyzing SWOT matrix about the industrial development of mining area; Then comprehensive weight are combined by subjective weight and objective weight; Finally the industrial evaluation value of mining area is got by comprehensive entropy evaluation of macroscopic and microscopic indicators. The priorities of the industrial development of mining area can be got by assessment results. The example proves that evaluation result of this model is effective and rational.
\end{abstract}

Keywords- mining area; industrial upgrading; entropy .

\section{INTRODUCTION}

Coal resources as a limited non-renewable resource is rapidly decreasing with the growth of energy consumption caused by economic growth, and the transition period of the industrial structure of mining area [1]. It is benefit for the regional economic development, employment of surplus workforce and social stability of mining area that a new leading industry is found and a smooth transition of industry is achieved before the advantages of the coal industry disappearing. So the industrial evaluation, optimization and upgrading must be made in time by mining area according to its actual situation and the industrial cycle theory.

\section{SWOT MATRIX OF INDUSTRIAL UPGRADING ANALYSIS}

With regard to the region that coal is the main resource, the industrial structure of the coal area must be adjusted according to the industrial cycle, and the leading mining industry also must be achieved by making full use of existing resources [2]. Although different coal area lie in different stage of resources exploitation, the paper analyzes the common characteristics of coal industry through SWOT matrix, and found the advantages, disadvantages, opportunities and challenges of the whole development of coal industry. It is can be seen Table 1 . According to the analysis of SWOT matrix, the superiority, inferiority, opportunity and threat of mining industry can be determined and choose the corresponding strategy.
TABLE I. SWOT MATRIX OF COAL INDUSTRY OF MINING AREA

\begin{tabular}{|c|c|c|}
\hline \multirow[b]{2}{*}{$\begin{array}{l}\text { Industrial } \\
\text { internal } \\
\text { environment }\end{array}$} & Strength & Weakness \\
\hline & $\begin{array}{l}\text { Comparatively abundant } \\
\text { reserves of resources; } \\
\text { Good cooperation with } \\
\text { the advanced area; } \\
\text { Better transport } \\
\text { infrastructure; } \\
\text { Enterprise reform and } \\
\text { operation of the Group } \\
\text { has gradually been } \\
\text { formed; } \\
\text { National energy policy } \\
\text { support. }\end{array}$ & $\begin{array}{l}\text { Low utilization and } \\
\text { waste; } \\
\text { Low efficiency and } \\
\text { insecurity; } \\
\text { The low quality of the } \\
\text { regional labor force; } \\
\text { Modern enterprise } \\
\text { system has not yet } \\
\text { been established; } \\
\text { Heavy burden of } \\
\text { leading industries. }\end{array}$ \\
\hline \multirow[b]{2}{*}{$\begin{array}{l}\text { Industrial } \\
\text { external } \\
\text { environment }\end{array}$} & Opportunity & Threat \\
\hline & $\begin{array}{l}\text { With development of } \\
\text { national economy, } \\
\text { demand for coal is } \\
\text { increasing; } \\
\text { Growth in domestic coal } \\
\text { demand helps coal market } \\
\text { demand increase. }\end{array}$ & $\begin{array}{l}\text { With accession to the } \\
\text { WTO, it suffers the } \\
\text { threat from abroad; } \\
\text { The strengthening of } \\
\text { environmental } \\
\text { protection policies; } \\
\text { Coal economic } \\
\text { environment affects the } \\
\text { development. }\end{array}$ \\
\hline
\end{tabular}

III. MODEL OF ENTROPY EVALUATION OF COAL INDUSTRY

\section{A. The index system established}

In this paper, the establishment of evaluation index system take these indicators as benchmarks which can clearly reflect the industrial sector changing, take these industrial sectors as base which are in accordance with the existing natural resources superiority and restriction in the industry evaluation, and get the relatively optimal result to combine with the actual situation from macro and micro two aspects. The indicators selected from micro level transversely reflects the merits and demerits of departments from internal industrial structure, and whether this kind of representatives industry is prospect and potential can be determined the role that sectors play in the market [3]. The indicators selected from macro level lengthways reflect the promising prospect of the region and provides the evidence that rationalization and optimization of industrial structure of the region [4]. The article adopts macro and micro two aspects indicators to analyze and evaluate the upgrading of industrial structure of coal mining, it is seen Figure 1. 


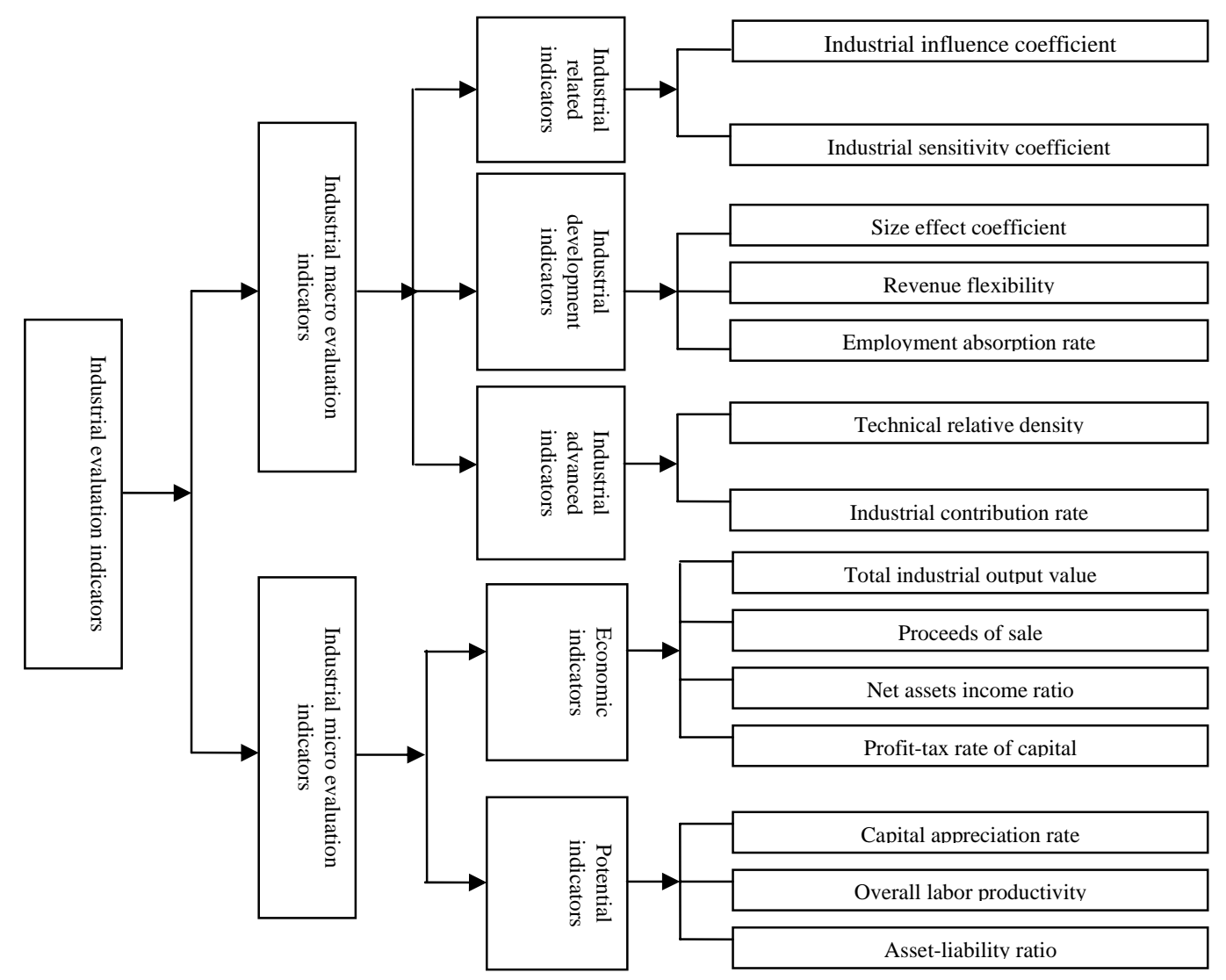

Figure 1. Evaluation index system of industrial structure

\section{B. The determination of weight indicators}

Step1: determination of subjective weight

An indirect way is used in AHP method that the indicator and index system role of describing one social phenomenon mutual comparison, and the results can be indicated by one special method. It is the 1-9 scaling law that creation of Satie AHP method proposed, and it is the foundation that constructs the judgment matrix. To calculate the largest eigenvector matrix and eigenvalue by using square root method and the root method steps is following [5].

The computation of nth square root each row elements $C_{i j}$ of every judgment matrix

$$
\overline{W_{i}}=\sqrt[n]{\prod_{j=1}^{n} \overline{C_{i j}}}(i, j=1,2, \ldots, n)
$$

The normalization of vector $\bar{W}=\left(\overline{W_{1}}, \overline{W_{2}} \ldots, \overline{W_{n}}\right)^{T}$

$$
W_{i}=\frac{\overline{W_{i}}}{\sum_{i=1}^{n} \overline{W_{i}}}
$$

So $W=\left(W_{1}, W_{2}, \ldots, W_{n}\right)^{T}$ is the eigenvector of the biggest eigenvalue, and that is the subjective weight of corresponding indicators

Step2: determination of objective weight
According to Entropy theory, the quantity and quality of the information that got from decision is the critical element of precision and reliability of decision. The information entropy of an indicator is the greater, the information content provided is the smaller, the degree of variation of the indicator value is the smaller, the role of comprehensive evaluation is the smaller and the entropy weight of the indicator is the smaller. Conversely, when the information entropy of an indicator is the smaller, the information content provided is the greater, the degree of variation of the indicator value is the greater, the role of comprehensive evaluation is the greater and the entropy weight of the indicator is the greater.

Supposed if the evaluating object (program) is $m$ and the evaluating indicators are $n$, the evaluation matrix of multiple objects about multiple indicators can be got by the principle of combination of qualitative and quantitative.

$$
R^{\prime}=\left[\begin{array}{cccc}
r_{11}^{\prime} & r_{12}^{\prime} & \cdots & r_{1 n}^{\prime} \\
r_{21}^{\prime} & r_{22}^{\prime} & \cdots & r_{2 n}^{\prime} \\
\vdots & \vdots & & \vdots \\
r_{m 1}^{\prime} & r_{m 2}^{\prime} & \cdots & r_{m n}^{\prime}
\end{array}\right]
$$

The positive treatment of the indicators that the value is greater and the effect is better

$$
r_{i j}=\frac{r_{i j}^{\prime}-\min \left\{r_{i j}^{\prime}\right\}}{\max _{i}\left\{r_{i j}^{\prime}\right\}-\min _{i}\left\{r_{i j}^{\prime}\right\}}, r_{i j} \in[0,1]
$$


The positive treatment of the indicators that the value is smaller and the effect is better

$$
r_{i j}=\frac{\max _{i}\left\{r_{i j}^{\prime}\right\}-r_{i j}^{\prime}}{\max _{i}\left\{r_{i j}^{\prime}\right\}-\min _{i}\left\{r_{i j}^{\prime}\right\}}, r_{i j} \in[0,1]
$$

The dimension eliminated is $R=\left(r_{i j}\right)_{m \times n}$.

In the evaluation, the entropy of the $j$ th indicator is defined

$$
H_{j}=-k \sum_{i=1}^{m} f_{i j} \ln f_{i j}
$$

In the formula $f_{i j}=\frac{r_{i j}}{\sum_{i=1}^{m} r_{i j}}, k=\frac{1}{\ln m}$.

Supposed if when $f_{i j}=0$ and $f_{i j} \ln f_{i j}=0, k$ can be choose to make $0 \leq H_{j} \leq 1$.

The entropy weight of the $j$ th indicator is defined

$$
\begin{gathered}
\omega_{j}=\frac{1-H_{j}}{n-\sum_{j=1}^{n} H_{j}} \\
0 \leq \omega_{j} \leq 1, \sum_{j=1}^{n} \omega_{j}=1 .
\end{gathered}
$$

So the objective weight of corresponding indicator is $\omega=\left(\omega_{1}, \omega_{2} \cdots \omega_{n}\right), 0 \leq \omega_{j} \leq 1$ and $\sum_{j=1}^{n} \omega_{j}=1$.

Step3: determination of comprehensive weight

Considering the judgment ability of deciders' experience and overall reflect the important of evaluating indicators, deciders must combine the subjective weight $W=$ $\left(W_{1}, W_{2}, \ldots, W_{n}\right)^{T} \quad$ with objective weight $\omega=\left(\omega_{1}, \omega_{2} \cdots \omega_{n}\right)$ of all indicators. It is combined by multiplication and is normalized to be comprehensive weight $\lambda$.

$$
\begin{gathered}
\lambda_{j}=\frac{W_{j} \omega_{j}}{\sum_{j=1}^{n} W_{j} \omega_{j}} \\
0 \leq \lambda_{j} \leq 1, \sum_{j=1}^{n} \lambda_{j}=1 .
\end{gathered}
$$

So the comprehensive weight is $\lambda=\left(\lambda_{1}, \lambda_{2} \cdots, \lambda_{n}\right)$.

The characteristics of comprehensive weight combined by multiplication are that when anyone of value of subjective weight and objective weight is small the comprehensive weight value is also small, only when two values are same important and the comprehensive value is important. This kind of method has multiplication effectiveness, can overall represent the evaluating result, and provides the best proposal for the optimization of multi objective industrial structure.

\section{The model of entropy evaluation established}

According to the standardization matrix $R=\left(r_{i j}\right)_{m \times n}$ including of micro and macro evaluating indicators, the micro and macro evaluating result of every object can be calculated by combining with the comprehensive weight $\lambda=\left(\lambda_{1}, \lambda_{2} \cdots, \lambda_{n}\right)$, and the result is following.

The result of micro evaluation is

$$
S_{i}^{\prime}=\sum_{j=1}^{n} \lambda_{j}\left(r_{j}^{*}-r_{i j}\right)
$$

The result of macro evaluation is

$$
S_{i}^{\prime \prime}=\sum_{j=1}^{n} \lambda_{j}\left(r_{j}^{*}-r_{i j}\right)
$$

In the formula, $r_{j}^{*}$ is the optimum value of $j$ th row of $R=\left(r_{i j}\right)_{m \times n}$.

Then the coefficient $\alpha(0 \leq \alpha \leq 1)$ can be determined by referring to actual situation and optimization proposal of industrial structure, and the final evaluating result is

$$
S_{i}=\alpha S_{i}^{\prime}+(1-\alpha) S_{i}^{\prime \prime}
$$

In the formula, $\alpha$ can be $0,0.5$, and 1 and so on.

According to the value of $S_{i}$, the every industrial sector can be ranked and the best industrial sector can be found from these.

\section{EXAMPLE}

This paper takes one of old mining area in central China as an example, and analyzes the development of coal enterprises and the change of industrial structure in this mining area. It can be seen from the value of micro evaluation in the bracket that the priority order is mining device (0.4842), service trade (0.1247), building industry (0.5539), coal chemical industry $(0.6415)$, coal generating electricity (0.9465) and mining and washing coal (0.7801). So based on the current advantage, the enterprise must strength the development of urgent need industrial sectors that includes mining device, service trade, building industry and coal chemical industry from the micro evaluating results. It can be seen from the value of macro evaluation in the bracket that the priority order is service trade (0.7293), mining and washing coal (0.8003), coal chemical industry (0.6422), building industry (0.6606), mining device (0.4421), coal generating electricity (0.5403).The macro evaluation focus on the economic development of area and potential development of industrial sector.

The coefficient $\alpha=0$. 5of model of entropy evaluation can be determined by combining the current sectors' economic development with the future industrial sectors' development in mining area. With comprehensive evaluation, the industrial upgrading and optimization evaluation results that takes the enterprise as the core is mining and washing coal (0.7902), coal generating electricity $(0.7434)$, service trade $(0.4270)$, building industry (0.6073), coal chemical industry (0.6419) and mining device (0.4632). The numerical value is $S_{i}$ in the bracket.

So it can be seen that the industrial sequence of coordinated development in mining area is service trade, coal device, building industry, coal chemical industry, coal 
generating electricity and mining and washing coal. When the mining and washing coal and coal generating electricity is stage of maturity, the industrial transition to meet the social requirements becomes more and more important.

\section{CONCLUSIONS}

With the establishment of SWOT model of mining industry, it can be easily analyzed that the strength, weakness, opportunity and challenge of the current industry in mining area. The model generalizes the name of the game, determines the direction of industrial development in mining area, and is also the foundation that coal enterprises make strategic regulation in mining area.

The industrial evaluation model of mining area based on entropy evaluation theory can effectively determine the optimal upgrading proposal of coal industry in mining area, and provide the theoretic guidance for the regional industrial adjustment and diversify development of coal enterprises.

\section{REFERENCES}

[1] Wu Qiang, Reconsideration on Transformation of Economy Structure in Mining Cities of China. Mining Research and Development, 3, pp.13-14,2004.

[2] Zhu Xun, The Situation and Development Strategy of Chinese Mining Industrial Cities in The 21st Century. China Mining Magazine, 8, pp.1-9, 2002.

[3] Athanasios G. Noulas, Production growth in the Hellenic banking industry: state versus private banks. Applied Financial Economics, 23, pp.223-228,1997.

[4] Michel Dietsch, Ana lozano-Vivas, How the environment determines banking efficiency: A comparative between French and Spanish industries. Journal of Banking\&Finance, 24, pp.985-1004,2000.

[5] Bialek W., Nemenman I., Tishby N, Predictability, complexity and learning. Neural Computation, 13, pp.2409-2463,2001. 